\title{
A University-Based Organizational Platform to Leverage Regional Economic Development
}

\section{Dr. David Elizandro, Tennessee Technological University}

David Elizandro is a professor of engineering at Tennessee Tech University where he teaches decision sciences in the Department of Computer Science. He earned a BS in chemical engineering, MBA, and $\mathrm{PhD}$ in industrial engineering. Professor Elizandro has served in a variety of administrative and leadership roles in science and engineering education.

Professor Elizandro has numerous publications and presentations in areas such as expert systems, data communications, distributed simulation, adaptive control systems, digital signal processing, and integrating technology into engineering education. He has also been an industry consultant on in discrete event modelling for strategic planning.

Professor Elizandro received the University Distinguished Faculty Award, Texas A\&M, Commerce and College of Engineering Brown-Henderson Award at Tennessee Tech University. He served as Governor's Representative for Highway Safety in Arkansas and member of the National Highway Safety Advisory Commission during the Jimmy Carter presidency. He is also a member of Tau Beta Pi, Alpha Pi Mu, and Upsilon Pi Epsilon honor societies. 


\title{
A University-based Organizational Platform to Leverage Regional Economic Development \\ David Elizandro, Janie Robbins Tennessee Tech University Susan Elkins, University South Carolina Mark Farley, Upper Cumberland Development District Doug Young, Clay County Three Star Program
}

\begin{abstract}
Over a half century ago Edwards Deming demonstrated that systems engineering concepts can be applied to any business or service enterprise. This paper critically reviews the engagement of an industrial engineering department in the design, development, and implementation of an integrated systems approach to administering regional economic development in the Upper Cumberland. The implementation was based on Deming's System of Profound Knowledge, the Appalachian Regional Commission definitions of Program Areas, and the Morrill Land Grant Act of 1862 with an expanded definition of economic development.
\end{abstract}

A cohort of industrial engineering seniors were instrumental in the design and development of the system. Similar to an AmeriCorps VISTA engagement, a characterization of the student perspective is the opportunity to strengthen an organization so it can continue to serve the needs of the community after the project has ended.

The system includes an organizational platform, a strategic planning process based on quantitative measures of regional employment, and a methodology for prioritizing regional economic development activities. University engagement enables the region to leverage analytical capability and provides Deming's Constancy of Purpose to regional economic development.

\section{Regional Profile}

The Upper Cumberland is at the intersection of the Central Basin, the Eastern Highland Rim and the Cumberland Plateau. As shown in Figure 1, the Upper Cumberland is centrally located the between metropolitan areas of Nashville, Knoxville, and Chattanooga. Interstate 40, one of the nation's most highly traveled arteries, provides regional access to the national interstate system.

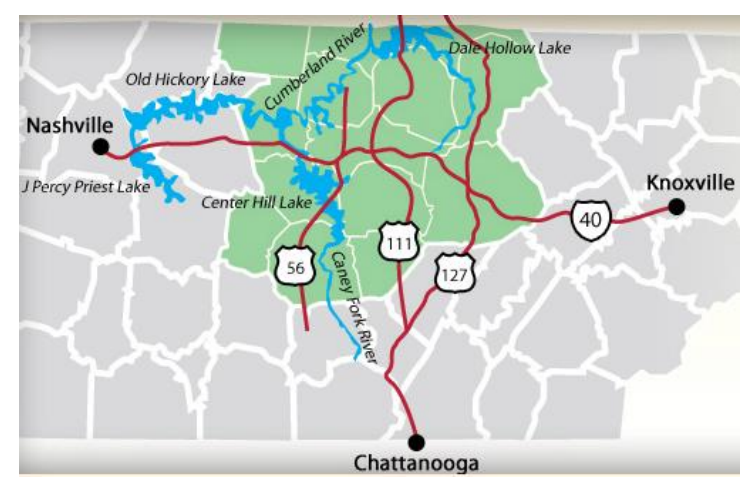

Figure 1: Upper Cumberland Region

Economic needs in the Upper Cumberland include developing infrastructure in remote rural areas; recruiting new companies; supporting and expanding current businesses and industries; improving K-12 educational infrastructure for a diverse economy; and developing a regional "brand identity" to leverage regional economic development activities. Strategic impediments to regional economic development include resources to address needs that have varying levels of complexity that are the result of subtle variations between jurisdictions within the region and sufficient technical support to prioritize regional needs.

Economic development stakeholders in the region are represented primarily by the local chambers of commerce and elected officials. The Upper Cumberland Development District (UCDD) and Upper Cumberland Human Resources Agency (UCHRA) have designated state and federal legal authority for coordinating regional development. Important funding sources for 
regional economic development include the Appalachian Regional Commission (ARC) which partners with the Tennessee Department of Economic and Community Development (ECD) to assist with administering $A R C$ 's economic development activities in the Upper Cumberland.

Higher education for U.S. citizens of average means may be linked directly to the history of land grant colleges. The land grant system was created by the Morrill Act of 1862 that gave states public land to establish a college that taught agriculture and the mechanical arts. One hundred and fifty years later and with a broader definition of economic development, industrial engineering degree programs in regional universities are an ideal platform to support rural development. The remainder of this paper describes a collaborative effort between $T T U$ industrial engineering department and constituents of Upper Cumberland regional development to support objectives of the Morrill Act.

\section{Regional Economic Development Environment}

Tennessee Tech University (TTU) received funding in 2011 for an Appalachian Regional Commission $(A R C)$ project to enhance the economic development infrastructure in the Upper Cumberland Region. The grant placed special emphasis on assistance for At-Risk and Distressed counties. In addition to subprojects, the grant supported the design, development, and proof of capability of an organizational platform and processes for administering regional economic development. Project goals were to:

1. Establish a culture of support for regional economic development within the University.

2. Create and nurture economic development partnerships between the University and the region.

3. Encourage faculty to develop economic development internship opportunities and related coursework for students.

4. Pursue funding that enables faculty to support regional economic development.

$T T U$, as a stakeholder in regional development, established Tech-REDI (Regional Economic Development Institute). The Tech-REDI mission was:

To leverage University resources that can facilitate efforts offederal, state, and local governments, as well as private industry, to enhance the economic environment in the Upper Cumberland.

The vision was:

To be recognized by officials in federal, state, and local government, as well as private industry, as a leader in the economic development of the Upper Cumberland region of Tennessee.

Tech-REDI Strategies were to:

1. Establish a culture of support for regional economic development.

2. Encourage faculty to offer economic development related internships, courses, and academic programs.

3. Pursue funding to support regional economic development. 
$T T U$ Strategies for assisting the region were to:

1. Facilitate collaborative efforts offederal, state and local governments, and private industry to enhance the economic environment in the region.

2. Provide innovation by conducting research on methods, processes, and facilities to enhance economic development.

3. Facilitate the transfer of scientific and technological knowledge, methods, processes, and facilities to regional economic development.

4. Assist with administering the regional strategic plan for economic development on behalf of the Upper Cumberland.

Concepts of reinventing government as a customer driven service began in the 1990s. The common thread of those concepts originate from the quality movement by W. Edwards Deming who proposed the management of integrated systems as the basis for quality for any production system. Deming formalized the approach into a System of Profound Knowledge (SPK).

As mentioned in the Regional Profile, a critical issue was lack of sufficient technical support to prioritize regional needs. The lack of a systemic approach to engage regional stakeholders exacerbated the issue. These related issues were motivation for TECH-REDI to lead an effort to create a university supported virtual organization based on principles of an SPK. The virtual organization and slightly revised definitions of ARC Program Areas are the platform for the regional initiative for administering economic development. The $A R C$ grant provided leverage to develop the $S P K$ which can be characterized as follows:

- An appreciation of a system: A systems approach enables regional development stakeholders to view the economic environment of the region in terms of internal and external interrelated component subsystems based on ARC definitions of Program Areas.

- The theory of knowledge: Regional development stakeholders must test opinions, theories, hypotheses, and beliefs on regional development against data to understand complex relationships in regional economic environment and determine changes necessary to achieve regional development. These theories must be developed, applied, and tested to advance knowledge of regional economic development in a systematic fashion using the Walter Shewhart Plan-Do-Study-Act (PDSA) cycle described in the section on Strategic Planning.

-A knowledge of variation: In performance analysis of the regional economic development related subsystems, the two sources of statistical variations are common and special cause. Common cause variations are usually predictable. Special cause variations represent unique events that are outside the system and therefore unpredictable. Methods for distinguishing sources and understanding causes of variation in regional economic data, as well as predicting behavior, are essential for testing knowledge of regional development.

- A knowledge of psychology: The proposed organizational structure, described in the next section, is a logical organizational which is an overlay of regional development stakeholders. Principles of the organization are the understanding that people are motivated primarily by intrinsic needs, including pride in workmanship and working with others to achieve regional development. This organizational platform was also the basis for administering $A R C$ funded subprojects.

The Upper Cumberland Tennessee, Regional Economic Development Initiative (UCTN-REDI) was the proposed logical organizational structure to leverage the technical capability to 
administer the $S P K$ and sustain Constancy of Purpose for economic development activities. $U C T N-R E D I$ design requirements were the ability to:

1. Efficiently identify activities with the most potential for improving the economic environment within the entire region.

2. Standardize and simplify project justification.

3. Facilitate faculty and student engagement by synchronizing economic development activities with the academic calendar.

4. Maintain a quantified inventory of economic development resources (Program Areas).

5. Develop an analytical approach for evaluating alternatives that address resource deficiencies.

6. Develop quantified criteria to assess relative project impact potential.

\section{III.Organizational Platform for Regional Development}

The UCTN-REDI leadership team consisted of the ECD Regional Director, UCDD Executive Director, TVA Regional Representative, USDA Rural Development Regional Representative, and a Tennessee Tech Representative. Advisory groups to UCTN-REDI were Regional Economic Development Stakeholders, REDS, and Regional Economic Development Council, REDC. REDS members are recognized regional economic development leaders with a strategic role to:

1. Strengthen the shared commitment across the region for regional economic development.

2. Provide advisory guidance and counsel on the Upper Cumberland's Regional Strategic Plan.

3. Provide a continuing means of organizing support for the Upper Cumberland Regional Economic Development Initiative.

$R E D C$ members are national and state leaders with perspective and domain knowledge necessary to provide expert advice on the $S P K$ related to economic development activities.

In the organization chart shown in Figure 2 , functional areas are staffed by an overlay of regional resources using a crowd-sourcing concept. Essential characteristics of crowd-sourcing as applied to administering regional economic development activities are:

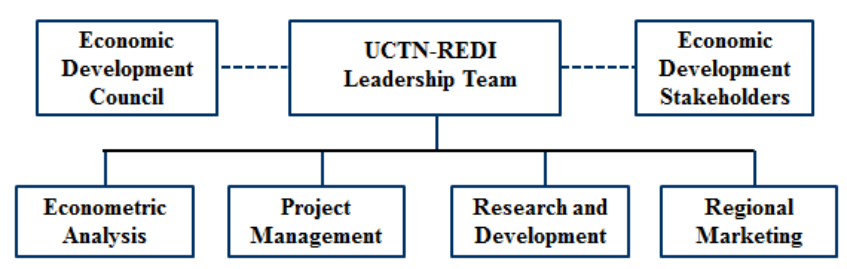

Figure 2: UCTN-REDI Organization Chart

1. An open call for participation by regional stakeholders in economic development of the Upper Cumberland.

2. An integration of regional stakeholders into the distributed UCTN-REDI organizational platform.

3. A channel to leverage regional experience and domain knowledge into solving regional economic development problems. 
As described in the following section, Econometric Analysis of regional data is a fundamental tool for Strategic Planning. The role of Research and Development is:

1. Conducting research on methods, processes, and facilities to improve Program Areas Metrics.

2. Ensuring new processes, applications, and services derived from research to improve Program Areas methods, processes, and facilities are available to UCTN-REDI.

To support Regional Marketing, an $A R C$ project funded university activities to develop a website to communicate the brand identity of the Upper Cumberland region as: A shared commitment to making the Upper Cumberland a better place to live, work, and play.

UCTN-REDI strategic planning is embedded in the functional areas which are coordinated by the university on behalf of the region. As a result, there are opportunities to develop a horizontal integration strategy for TTU colleges to engage in regional development.

\section{Strategic Planning}

In Figure 3, private and public resources are used to develop systems and processes that improve the regional employment metrics for quality of jobs data such as employment rates, number of jobs, and job compensation. Deming's $S P K$ is

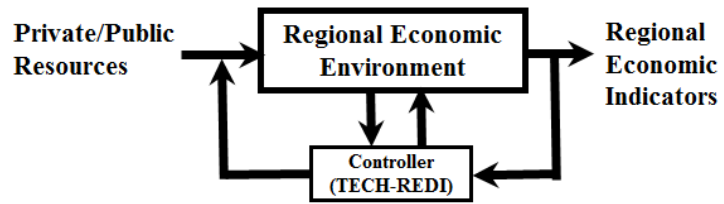

Figure 3: Regional Development System embedded into ARC Program Area definitions and the Controller administers the internal and external interrelated subsystems designed to achieve regional development.

Controller activities are an implementation of the Shewhart Cycle, developed by Walter Shewhart at Bell Laboratories during the 1930s. The Plan-Do-Study-Act (PDSA) cycle in Figure 4 is a systematic process of theory and application of knowledge that enables regional development stakeholders to characterize relationships between $A R C$ Program Areas and regional development and to achieve a cycle of improvements in regional employment metrics. Cycle definitions are as follows:

- Plan: Configure subsystem changes based on the analysis of Program Area Metrics.

- Do: Implement Projects to reconfigure the subsystem to

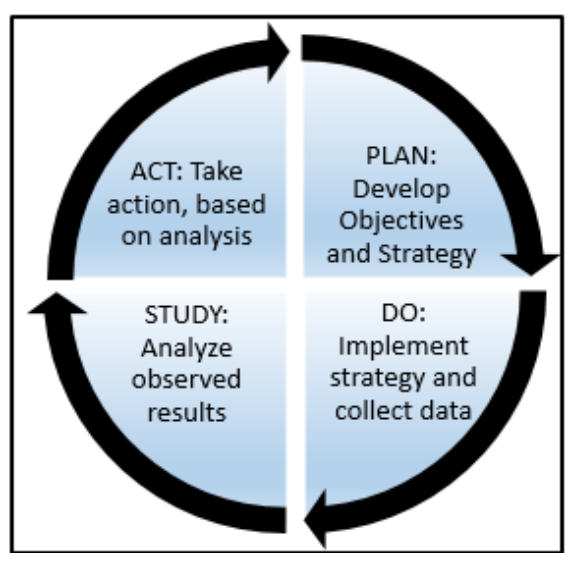

Figure 4:Shewhart Cycle achieve desired changes in Program Area Metrics.

- Study: Analyze the effects on Program Area Metrics by comparing observed and expected results.

- Act: Take action based on results of the analysis. If expected Program Area Metrics were not achieved, initiate the cycle again with different Projects. Use what was learned from the analysis to plan additional improvements. 
As shown in Figure 5, Projects support Program Areas that support Jobs Initiatives. The systems design criteria is that changes to Employment Metrics are dependent on changes to Program Area Metrics which are dependent on changes to Project Metrics. An example of a program area description with a related project is as follows:

Program Area Education: Educational infrastructure for K-12 educational programs, technology centers, community colleges, and research and comprehensive universities. Also included are the

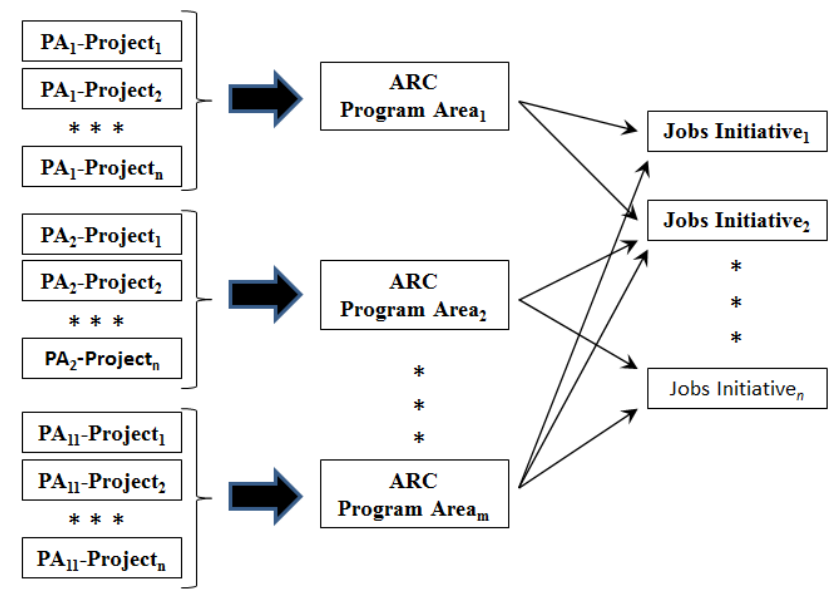

Figure 5 Job Initiatives Mapping administrators, teachers, and curricula for each source of graduates.

Program Area Objective: Increase post-secondary (technology centers, community colleges, and university) graduation rates by a specific amount.

Project: Regional Counties Project Lead the Way (PLTW)

Project Objective: To increase the number of high school graduates prepared for higher education engineering and engineering technology programs.

Project Methods: Offer an Elective Focus (3 courses) in PLTW pre-engineering in Clay, Pickett, White, and Jackson counties by funding a Jackson County teacher, who is a licensed civil engineer, to attend training for the Project Lead the Way training in the Civil Engineering and Architecture course and supplies to teach the course.

EDC assisted with administering the Plan-Do-Study-Act (PDSA) cycle by providing insight on:

- Benchmarking Program Area and Program Area Metrics.

- Developing Target Levels for Program Area Metrics.

- Developing and monitoring Program Area "Score Cards".

- Assessing impact potential of proposed projects.

In Figure 6 is an integrated systems view of the Strategic Planning Cycle with an expanded explanation of Controller activities. The cycle begins with a Jobs Initiative that includes a quantitative articulation of Employment Metrics that identifies a segment of the region with job creation potential. The downward arrow from Jobs Initiative( $s$ ) represents targets for Program Area Objectives and Metrics.

Projects activities and corresponding Metrics are represented by the downward arrow from Program Area(s) to Projects(s). The return arrow to Program

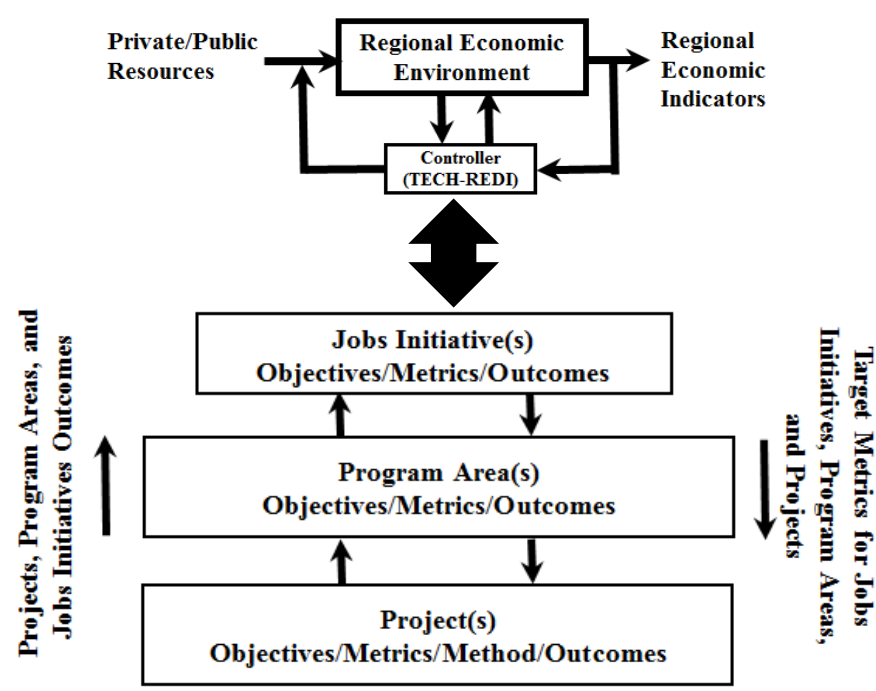

Figure 6: Integrated Strategic Planning Activities 
Area(s) represents actual changes in Project Metrics; the return arrow to Jobs Initiative(s) represents actual changes in Program Area Metrics.

\section{IV-a.Program Area(s)}

Program Area specifications include:

- System Components: Program Area resources.

- Objectives: Qualitative description of desired improvements in system components.

- Metrics: Quantitative measures of Program Area Objectives.

- Outcomes: Expected changes in the Program Area Metrics.

Orthogonal definitions of Program Area(s) ensures a modular approach for adding and removing

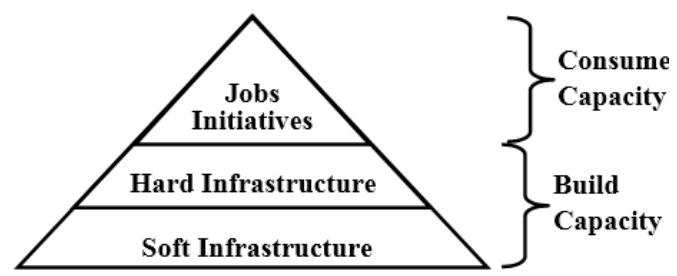

Soft Infrastructure: Organizational structure and processes to administer regional economic development.

Hard Infrastructure: Traditional ARC Program Areas (excluding human capital).

Jobs Initiatives: Integrated Program Area(s) activities to improve or maintain Regional Employment Metrics.

Figure 7: Program Area(s) Pyramid

Program Areas to/from the Strategic Plan. The foundations of Program Area design is reflected in Figure 7. The base is the ARC Program Areas of Leadership and Capacity Building (Soft Infrastructure). Hard Infrastructure refers to other ARC Program Areas important to regional development. In the apex are Jobs Initiatives that consume Hard Infrastructure resources to create jobs. The initial set of TECH-REDI Program Areas were:

- Asset Based Development: Underutilized natural resources and nonperforming (underperforming) structural assets which may be leveraged to create jobs by producing goods or services (farms, industrial parks, and business incubators) while preserving the character of the environment. Examples are:

- Natural Resources: farming through specialized agricultural development; processing specialty food items; fish farming and organic farming; and sustainable timber harvesting and value-added processing.

- Structural Assets: historic buildings, abandoned railroads, old mines, previously used industrial land contaminated by low concentrations of pollution.

- Community Infrastructure: Assets that provide water and wastewater services to support business and community development, and alleviate public and environmental health hazards.

- Education: Educational infrastructure for K-12 educational programs, technology centers, community colleges, and research and comprehensive universities. Also included are the administrators, teachers, and curricula for each source of graduates.

- Leadership Development and Capacity Building: The organizational platform to administer Deming's SPK is reflected in:

- Partnerships and collaboration among government, business, and nonprofit and philanthropic sectors.

- Analytical tools and technical support available to the organization.

- Tourism: Cultural assets of the arts, traditions, and musical heritage and the ecological assets such as mountains, scenic rivers, and forests and for outdoor sports such as fishing, camping, white water rafting, and hiking. 
In the Figure 8 system representation for the Education Program Area, Metrics are graduation, matriculation, and abnormal system exit rates by discipline for the high schools, community colleges, colleges of applied technology, and $T T U$.

The Figure 9 fishbone diagram is a root cause analysis tool for developing a Plan for the PDSA cycle to improve Program Area Metrics. In the diagram shown, Program Area domain knowledge is the basis for strategic planning to address the Program Area primary and secondary resource deficiencies. The effort determines what resources are necessary to affect changes to Program Area Metrics. From Figures 4 and 5, resource deficiencies are the basis for project development.

IV-b. Project(s) Management Project Management ensures project activities conform to contract specifications and that data necessary to assess project effectiveness are available. Project specifications include:

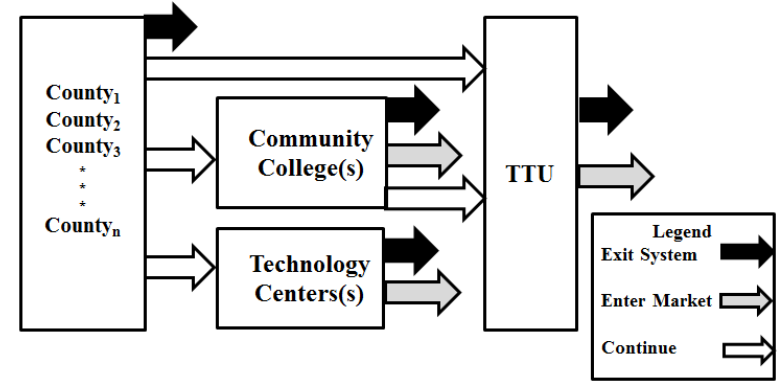

Figure 8: Program Area Education System

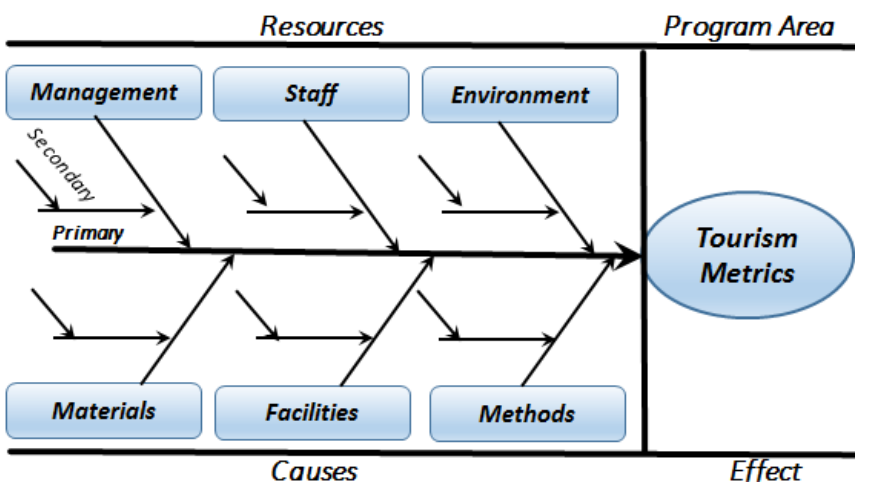

Figure 9: Program Area Root Cause Analysis

- Objectives: Qualitative reference to a Program Area.

- Metrics: Quantitative measures of Project Objectives.

- Methods: Project activities to achieve Project Objectives.

- Outcomes: Expected changes in Project Metrics.

Objectives address baseline improvements in Program Area Infrastructure or a Jobs Initiative. To reflect the distinction, a Project is designated as a Build Capacity or Consume Capacity project.

Build Capacity Weighting Factors reflect Project importance to a Program Area. Consume Capacity Weighting Factors are relative measures of importance to a $J o b$ Initiative. In Figure 10 Program Area Weight Factors for Build and Consume Capacity Project are inversely related. Another EDC role is to provide and independent assessment of Program Area Weighting Factors for potential projects.

Important to a project success is management capability of project administrators. The assessment scale in Figure 11 measures perceived ability of administrators to implement the
Program Area Project Weighting Factor - Consume Capacity

5 - Major competitive advantage

4 - Minor competitive advantage

3 - Neither a competitive disadvantage or advantage

2 - Minor competitive disadvantage

1 - Major competitive disadvantage

Program Area Project Weighting Factor - Build Capacity

5 - Major competitive disadvantage

4 - Minor competitive disadvantage

3 - Neither a competitive disadvantage or advantage

2 - Minor competitive advantage

1 - Major competitive advantage

Figure 10: Project Evaluation Weight Factors 
project and Weights reflect the importance of that capability. The EDS provides an independent assessment of management capability.

The Project Scores for a Consume Capacity Projects in Figure 12 are an average of $E D C$ and $E D S$ scores. Notice that the Weighted Project Score includes the Director Project Score from Figure 10. The raw score indicates the project's impact potential on its related Program Area Objective. In general, a Jobs Initiative

\begin{tabular}{|c|c|c|c|c|c|c|c|}
\hline \multirow{3}{*}{\multicolumn{2}{|c|}{$\begin{array}{c}\text { Management } \\
\text { Capacity }\end{array}$}} & \multicolumn{6}{|c|}{ EPRD Associate Director's Project } \\
\hline & & \multirow{2}{*}{\multicolumn{2}{|c|}{ Impact Potential | }} & \multicolumn{3}{|c|}{ Questionable } & Neutra \\
\hline & & & & 0 & \begin{tabular}{l|l}
1 & 2 \\
\end{tabular} & 3 & 4 \\
\hline Stakeholder Preparation & wt. & Score & \begin{tabular}{|c|} 
Weighted \\
Score
\end{tabular} & Score & $\begin{array}{c}\text { Weighted } \\
\text { Score }\end{array}$ & Score & $\begin{array}{c}\text { Weighted } \\
\text { Score }\end{array}$ \\
\hline Actively involved in the project & 5 & 9 & 45 & & 0 & & 0 \\
\hline $\begin{array}{l}\text { Experience relevant to project } \\
\text { activities }\end{array}$ & 5 & 9 & 45 & & 0 & & 0 \\
\hline $\begin{array}{l}\text { Adequate project management } \\
\text { skills }\end{array}$ & 5 & & 0 & & 0 & & 0 \\
\hline Adequate project staffing & 5 & & 0 & & 0 & & 0 \\
\hline Authority to manage the project & 5 & & 0 & & 0 & & 0 \\
\hline Roles are clearly defined & 5 & & 0 & & 0 & & 0 \\
\hline Director Project Score & & & 45 & & 0 & & 0 \\
\hline
\end{tabular}

Figure 11: Administrative Ability for Project Management project has higher Program Area Weights.

\section{IV-c. Jobs Initiatives}

A Jobs Initiative is a group of projects across one or more Program Areas. Jobs data, by industrial sector, is a common Jobs Initiative Metrics. Other metrics are employment rates and population profiles of the region.

An Excel-based Jobs Metrics Modeling System developed by students supports Jobs Initiatives development. For example cumulative jobs numbers by sector of the economy for Clay County are presented in Figure 13. The fourth band in the graph represents tourism and hospitality.

Another feature of the modeling systems is the

\begin{tabular}{|c|c|c|c|c|c|c|c|c|c|c|c|}
\hline \multirow{4}{*}{$\begin{array}{l}\text { Consume } \\
\text { Capacity }\end{array}$} & & \multicolumn{10}{|c|}{ EDC Project Evaluation Report } \\
\hline & & \multirow{2}{*}{\multicolumn{2}{|c|}{ Impact Potential | }} & \multicolumn{2}{|c|}{ Questionable } & \multicolumn{2}{|c|}{ Neutral } & \multicolumn{2}{|c|}{ I } & \multicolumn{2}{|l|}{ Positive } \\
\hline & & & & $0 \quad 1$ & \begin{tabular}{l|l}
1 & 2 \\
\end{tabular} & 31 & \begin{tabular}{l|l}
4 & 5 \\
\end{tabular} & 6 & $7 \quad 8$ & \begin{tabular}{l|l}
8 & 9
\end{tabular} & 10 \\
\hline & & \multicolumn{2}{|c|}{$\frac{\text { Project \# }}{\underline{1}}$} & \multicolumn{2}{|c|}{$\begin{array}{c}\text { Project \# } \\
2\end{array}$} & \multicolumn{2}{|c|}{$\begin{array}{c}\text { Project \# } \\
3\end{array}$} & \multicolumn{2}{|c|}{$\begin{array}{c}\text { Project \# } \\
4\end{array}$} & \multicolumn{2}{|c|}{$\begin{array}{l}\text { Project \# } \\
5\end{array}$} \\
\hline Program Areas & wt. & Score & $\begin{array}{c}\text { Weighted } \\
\text { Score }\end{array}$ & Score & \begin{tabular}{|c|} 
Weighted \\
Score
\end{tabular} & Score & \begin{tabular}{|c|} 
Weighted \\
Score
\end{tabular} & Score & \begin{tabular}{|c|} 
Weighted \\
Score
\end{tabular} & Score & $\begin{array}{c}\text { Weighted } \\
\text { Score }\end{array}$ \\
\hline Asset-based Development & 5 & 9 & 45 & & \begin{tabular}{|l|l|}
0 & \\
\end{tabular} & & \begin{tabular}{|l|}
0 \\
0
\end{tabular} & & \begin{tabular}{|l|}
0 \\
0
\end{tabular} & & 0 \\
\hline Community Infrastructure & 5 & & 0 & & 0 & & 0 & & 0 & & 0 \\
\hline Education and Training & 5 & & 0 & & 0 & & 0 & & 0 & & 0 \\
\hline Energy & 5 & & 0 & & 0 & & 0 & & 0 & & 0 \\
\hline $\begin{array}{l}\text { Entrepreneurship and } \\
\text { Business Development }\end{array}$ & 5 & & 0 & & 0 & & 0 & & 0 & & 0 \\
\hline Export and Trade Development & 5 & & 0 & & 0 & & 0 & & 0 & & 0 \\
\hline Health & 5 & 3 & 15 & & 0 & & 0 & & 0 & & 0 \\
\hline $\begin{array}{l}\text { Leadership Development and } \\
\text { Capacity Building }\end{array}$ & 5 & & 0 & & 0 & & 0 & & 0 & & 0 \\
\hline Telecommunications & 5 & & 0 & & 0 & & 0 & & 0 & & 0 \\
\hline Tourism Development & 5 & 8 & 40 & & 0 & & 0 & & 0 & & 0 \\
\hline Transportation and Highways & 5 & & 0 & & 0 & & 0 & & 0 & & 0 \\
\hline EDC Project Score & & & 100 & & 0 & & 0 & & 0 & & 0 \\
\hline Weighted Project Score & & & 89 & & 0 & & 0 & & 0 & & 0 \\
\hline EDC Score $\%=$ & 80 & & & & & & & & & & \\
\hline Director Score $\%=$ & 20 & & & & & & & & & & \\
\hline
\end{tabular}

Figure 12: Project Scoring Rubric

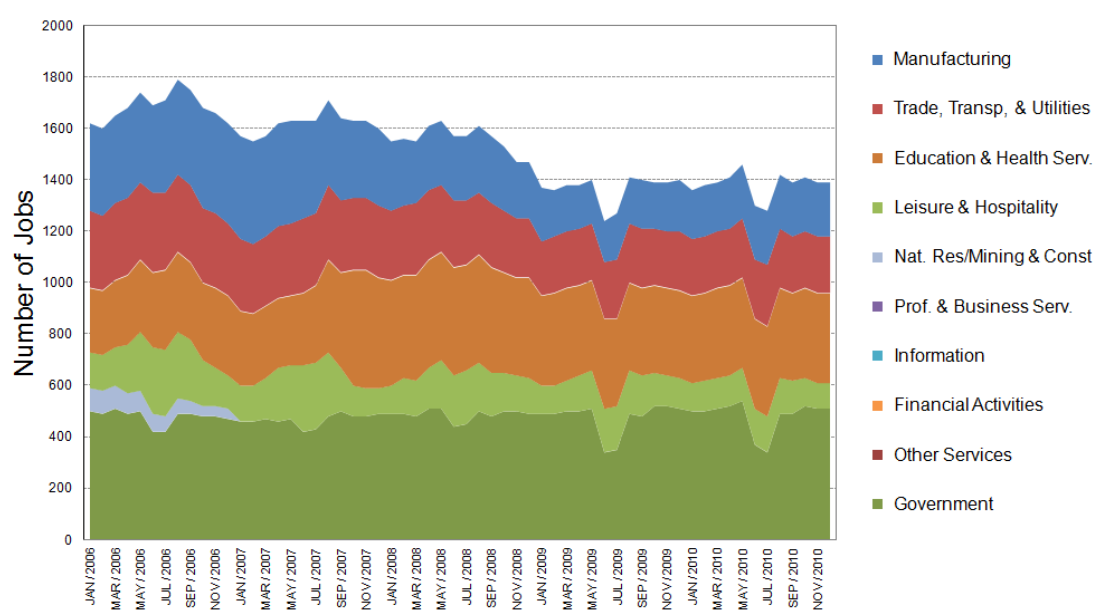

Figure 13: Clay County Jobs by Economic Sector 
ability to forecast regional jobs data. In Figure 14 are jobs forecast for Clay County. Forecasting techniques include Winter's Algorithm, the Decomposition Algorithm and deseasonalized data.

Students also developed an Excelbased optimization model to maximize the total impact on economic development, subject to budget constraints for project funding. The model considers the projected impact of all projects in the region. Impact

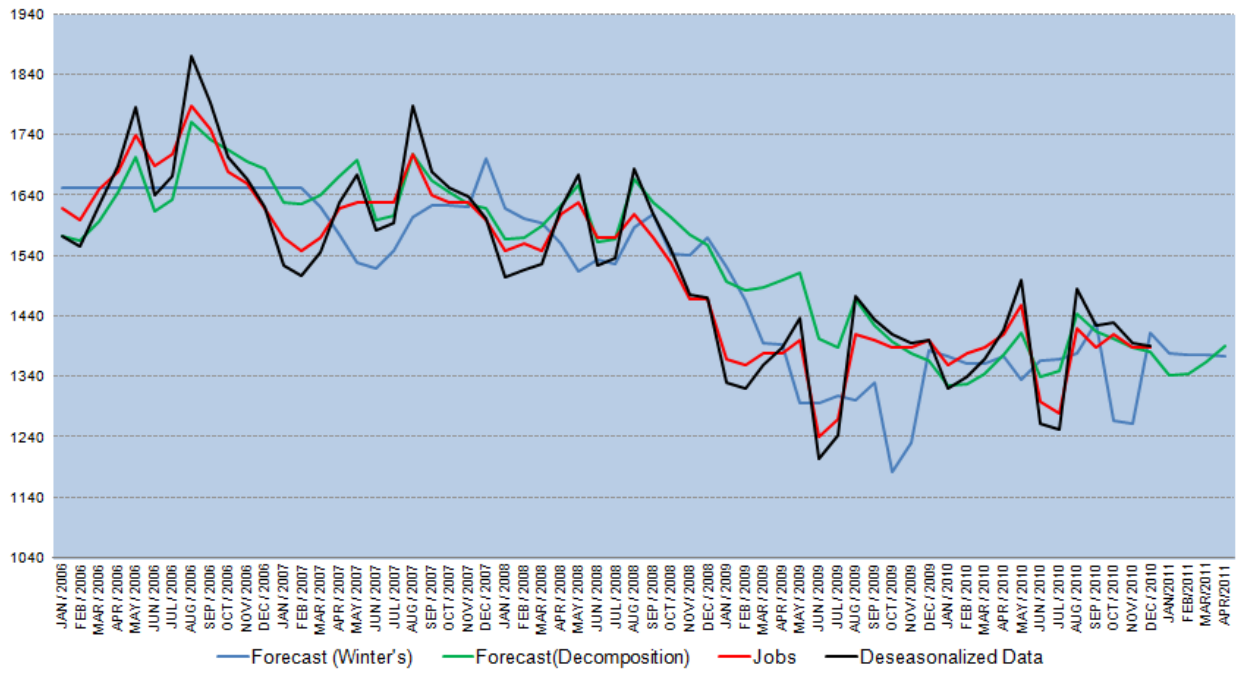

Figure 14: Jobs Forecast for Clay County potential metrics are from the previously described project rankings. Formulation of the model is:

$$
\begin{aligned}
& N=\text { Number of jurisdictions in the Region } \\
& M_{i}=\text { Number of projects in jurisdiction } i \\
& W_{i j}=\text { Weighted Impact Potential of Project } j \text { in Jurisdiction } i \\
& C_{i j}=\text { Cost of project } i \text { in jurisdiction } j \\
& x_{i j}=1 \text { when project } j \text { in jurisdiction } i \text { is selected; } 0 \text { otherwise } \\
& \text { Maximize Weighted Projects Impact Potential } \\
& \quad \sum_{i=1}^{N} \sum_{j=1}^{M_{i}} W_{i j} x_{i j} \\
& \quad \sum_{i=1}^{N} \sum_{j=1}^{M_{i}} C_{i j} x_{i j} \leq \text { Current Budget Allocation } \\
& \text { and other regional project constraints }
\end{aligned}
$$

As indicated in the last line of the model definition, other project constraints may be included in the model. For example, the model could distinguish the importance of overlapping projects. The approach to developing a Jobs Initiative is shown in Figure 15. Program Area deficiencies important to an initiative are identified. Then Figure 8 fishbone diagrams for each Program Area identified becomes the basis for an integrated Job Initiative shown in Figure 4.

Because of $U C T N-R E D I$ implementation delays and limited access to necessary data systems, a complete cycle of the Plan-Do-Study-Act (PDSA) Cycle and the development of a Jobs Initiative were not completed. 


\section{UCTN-REDI Implementation} Major portions of $U C T N-R E D I$ were successfully implemented. Planning processes were operational and most of the designs for Program Area data systems were completed; however, populating these data systems required modifications to state and regional data collection procedures.

Deming's Constancy of Purpose was critically important to sustaining the UCTN-REDI organizational platform. For example, during a major portion of the $A R C$ grant, the lack of focus on the $S P K$ was problematic. Broad based expectations of regional stakeholders were that the $A R C$ grant only funded regional sub-grants, the historical approach to regional development. Lack of focus was also the result of changes in organizational leadership. During the life of the project, personnel changes included a change in the governor's office; new leadership in the Department of Economic and Community Development; an UCDD Executive Director resignation; a retirement by the TTU President who was instrumental in securing the $A R C$ grant; and the TTU VicePresident with primary responsibility for the grant accepted a position at another university. Also, in the first election after expiration of the $A R C$ grant, 10 of the 14 county mayors in the region were newly elected officials.

\section{Student Engagement}

A group of seniors in industrial engineering was critical to the project development and implementation. These students were among the cohort of the last $T T U$ industrial engineering graduates of the program because the degree was terminated prior to the start of the $A R C$ grant. Five of them had a major role in every phase of the effort. They began work on this project as part of their project management class and continued the effort in their senior design project.

These students had the unique opportunity to apply industrial engineering tools and techniques in a nontraditional environment and create a systems engineering structure to administer regional economic development. From a student perspective, this project was identical to an AmeriCorps VISTA engagement. Their website characterize the AmeriCorps experience as strengthening an organization so it can continue to serve the needs of the community once AmeriCorps VISTA's support has ended.

Students conducted interviews of state, county, and city officials to gather project related information and presented finding and recommendations throughout the project. Student deliverables included:

- Process flow chart for administering regional projects.

- County and regional employment forecast models.

- System definitions and performance metrics for economic development program areas.

- SharePoint platform to administer strategic planning and project management for the regional economic stakeholders.

- Developing the resource allocation model for project selection. 


\section{Conclusions}

Initiatives are invariably high risk because of uncertainties and inherently long learning curves associated with implementation. Numerous case studies describe successful initiatives.

Estimates are that over 90 percent of initiatives fail and rarely presented as case studies. This projects merits consideration because the UCTN-REDI virtual organization concept that includes "hands-on" university engagement to leverage regional development is largely unprecedented.

The project also demonstrated the importance of TTU providing UCTN-REDI with technical capability to administer the $S P K$ on behalf of the region. Near the end of the project there was increasing support to continue the effort. Several ECD administrators considered UCTN-REDI as a prototype for university-regional partnerships in rural Tennessee.

$U C T N-R E D I$ effectively ended with $T T U$ 's disengagement which occurred when the ARC grant ended. Leadership changes in key regional development stakeholder organizations caused Constancy of Purpose to be a critical issue. The importance of Deming's SPK as an approach to administering development was not impugned and the region continues to be challenged by the need for an integrated strategy for regional development. Students involved in the project had graduated prior to project termination. In follow-up conversations with these students on status of their efforts, all expressed disappointment that their work was not the seed for continuation of TECH-REDI.

\section{References}

1. History and Overview of Land Grant College System, http://www.nap.edu/read/4980/chapter/2

2. Using Regional Economic Development Strategies to Diagnose and Treat Skills Gaps, Rob Sentz, https://www.forbes.com

3. Emerging Principles in State and Local Economic Development: A Benchmarking Tool, Hubert H. Humphrey Institute of Public Affairs

4. Rethinking Federal Policy for Regional Economic Development, Mark Drabenstott, https://www.kansascityfed.org

5. Appalachian Regional Commission (2015). https://www.ARC.gov

6. The Deming Institute, https://www.deming.org/theman/theories

7. AmeriCorps VISTA, http://www.nationalservice.gov/programs/americorps/americorps-vista

David Elizandro is a professor of engineering at $T T U$ where he teaches decision sciences in the Department of Computer Science. Professor Elizandro has served in a variety of administrative and leadership roles in science and engineering education. Professor Elizandro received the University Distinguished Faculty Award, Texas A\&M, Commerce and College of Engineering Brown-Henderson Award at Tennessee Tech University. He served as Governor's Representative for Highway Safety in Arkansas and member of the National Highway Safety Advisory Commission during the Jimmy Carter presidency.

Janie Robbins is associate director of Extended Programs and Regional Development in the College of Interdisciplinary Studies at $T T U$ where she coordinates $2+2$ programs at off-campus sites in partnership with Motlow State and Chattanooga State community colleges. She also teaches as an adjunct faculty member for the School of Interdisciplinary Studies. Ms. Robbins assists several $T T U$ departments in their educational outreach initiatives, including the partnership between TTU's Manufacturing Engineering Technology Department and the 
Volkswagen Academy in Chattanooga. She also serves on several community boards involving economic and community development.

Susan Elkins is currently Chancellor of the University of South Carolina, Palmetto College. Prior to that. she led Tennessee Tech University's outreach as Director of Extended Education, Dean of the School of Interdisciplinary Studies and Extended Education, and Vice President of Extended Programs and Regional Development. Dr. Elkins was the recipient of the 2015 Leadership Award from the Association of Continuing Higher Education International and is a past chair of the Association of Continuing Higher Education South.

Mark Farley serves as the Executive Director of the Upper Cumberland Development District located in Cookeville, TN. The Development District serves as the regional economic development organization by administering state and federal programs for the Economic Development Administration and Appalachian Regional Commission as well as others. Prior to serving at the Development District, Mark was the Director of Finance for White County, TN.

Doug Young has spent a lifetime living and working in rural Tennessee. He has served as a teacher, coach, principal, superintendent, educational facility planner, and adjunct professor for the past fifty-two years. He has degrees from Middle Tennessee State University, Tennessee Technological University, and the University of Tennessee. He has worked in both the public and private sectors. He also serves on several boards and volunteers in several civic activities. 